\title{
Central Line Management
}

National Cancer Institute

\section{Source}

National Cancer Institute. Central Line Management. NCI Thesaurus. Code C15758.

Any activity related to the care and supervision of a central venous catheter. 